\title{
Traumatic Travels - A Review of Accidental Death and Injury in International Travellers
}

\author{
Ian James Long ${ }^{1}$, Gerard Thomas Flaherty ${ }^{1,2^{*}}$ \\ ${ }^{1}$ School of Medicine, National University of Ireland Galway, Ireland \\ ${ }^{2}$ School of Medicine, International Medical University, Kuala Lumpur, Malaysia
}

Corresponding Author: Gerard Thomas Flaherty, MD, Professor, School of Medicine, National University of Ireland Galway, Ireland. Tel: +35-391495469, Email: gerard.flaherty@nuigalway.ie.

Received November 30, 2017; Accepted February 13, 2018, 2017; Online Published April 9, 2018, 2018

\begin{abstract}
Insufficient attention has been paid to physical trauma as a cause of morbidity and mortality in international travellers, despite travellers themselves ranking it among their most important pre-travel health concerns. Road traffic collisions (RTCs) are the most common cause of death in younger travellers. One of the significant factors contributing to motorist accidents is tourists' disorientation in a foreign environment. This is compounded by jet lag and travel fatigue, unfamiliarity with a hired vehicle, local road rules, weather, terrain, distracting scenery and driving on the wrong side of the road, the last factor accounting for the highest percentage of road crash-related injuries. Many of the traumatic risks of travel can be anticipated by performing a careful risk assessment. Travellers should receive targeted advice in relation to prevention of RTCs, adventure sports injuries, large mammal attacks, stampedes and breaches to their personal safety and security. This narrative review article draws attention to these risks and offers practical advice for mitigating the risk to travellers.

Keywords: Travel, Trauma, Injury, Accident, Road Traffic Collision, Stampede
\end{abstract}

Citation: Long IJ, Flaherty GT. Traumatic travels - a review of accidental death and injury in international travellers. Int J Travel Med Glob Health. 2018;6(2):48-53. doi:10.15171/ijtmgh.2018.10.

\section{Introduction}

With the rapid growth of globalised travel, forecasted to exceed 1.8 billion arrivals by $2030,{ }^{1}$ it is essential that travellers should be made more aware of the risk of traumatic injury and death in unfamiliar environments and possible prevention strategies. Traumatic death in a traveller is particularly distressing and repatriation is especially complicated. ${ }^{2}$ Despite this, a recent bibliometric analysis of travel medicine literature confirms the lack of emphasis on this subject in academic travel medicine. ${ }^{3}$ The scope of this review is to consider the various facets of physical trauma during international travel and to stimulate further original research in this area. Although there is a wide range of causes of travel-related mortality, this narrative review article will focus on road traffic collisions (RTCs), adventure sports, wildlife attacks, and homicides.

\section{Methods}

\section{Search Strategy}

English-language articles indexed on Scopus and PubMed databases published through November 2017 were retrieved using variations of the search terms 'accidental death' or 'trauma' combined with 'international travel' and 'travel'. Use of the search terms 'travel AND trauma' alone yielded
1987 articles on the PubMed database, a small proportion of which were relevant to travel medicine. Article titles and abstracts were screened to assess relevance to the theme of traumatic travel. Additional publications were obtained from the reference lists of articles. Articles published in the last 10 years were given preference.

\section{Results \\ Trauma-Related Mortality}

In 2010, out of 52.8 million deaths globally, $65 \%$ was attributable to non-communicable diseases and approximately half of these were due to cardiovascular diseases. ${ }^{4}$ The next most common causes of death were infectious diseases and injuries. This pattern of prevalence also appears to be similar among overseas travellers, where cardiovascular disease accounts for the majority of deaths, followed by traumatic injuries. ${ }^{5-8}$ RTCs are the most prevalent cause of injury (25\%-60\%) resulting in traveller fatalities. ${ }^{9}$ Other causes of injuries include falls, human stampedes, animal attacks, injuries sustained while engaging in adventure sports, aviation crashes, natural disasters, and homicide. Although the probability of any of these events occurring is lower than vehicular trauma, they make a notable contribution to the overall mortality burden. 


\section{Road Traffic Collisions}

Road traffic accidents are the leading cause of death in overseas travellers, exacerbated by the fact that travellers are at a greater risk of being involved in a collision than local inhabitants. This is evident from a US-based study, where the figure for US citizens' injuries abroad due to vehicular crashes was $13 \%$ higher than that for local citizens. The same study drew similar conclusions in seven out of the ten regions studied. ${ }^{5}$ Additionally, in Bermuda, road trauma involving motorcycle usage among tourists was six times greater than the rate for the local population. ${ }^{10}$ Underlying contributory factors include tourists' disorientation in a new environment, travellers' alcohol consumption, the socio-economic circumstances of the destination country and the level of local enforcement of safety regulations.

One of the significant factors contributing to RTCs is tourists' disorientation when entering a foreign environment. This is compounded by jet lag and travel fatigue, unfamiliarity with a hired vehicle, local road rules, weather, terrain, distracting scenery and driving on the wrong side of the road, the last factor accounting for the highest percentage of road crashrelated injuries. ${ }^{11-14}$ Alcohol consumption among travellers is a significant contributor to motorist trauma. One study demonstrated that alcohol consumption was the primary cause of RTCs among travellers to Greece, particularly among those of Eastern European nationality. ${ }^{15}$ In addition, studies have shown that tourists are less likely to observe local drinking and driving laws, thereby compounding the problem. ${ }^{11}$

The economic status of a country is also a key factor when considering the prevalence of RTCs; a study conducted by the World Health Organization showed that RTCs are most prevalent in low- and middle-income countries. ${ }^{16}$ This is primarily due to poorly financed and managed national transportation and medical infrastructure, which manifests in ill-maintained roads that lack basic safety infrastructure such as street lighting, guard rails and hard shoulders. ${ }^{11,12}$ The problem is magnified by poorly qualified drivers, and badly maintained vehicles. In severe vehicular accidents, most victims do not have access to pre-hospital emergency care services and rely on other road users for assistance. ${ }^{11}$ It has been reported that up to $80 \%$ of patients die before reaching a medical facility. ${ }^{13}$ Furthermore, in many medical facilities in economically deprived areas of Africa and Southeast Asia, over $45 \%$ of emergency healthcare providers lack specific trauma care training. ${ }^{17}$ This leads to reduced capacity to effectively treat the injured, leading to increased mortality, for otherwise potentially treatable trauma. In contrast, $7 \%$ of the world's population, mainly in high income countries, have access to sufficient funding and an adequate safety framework. ${ }^{11}$ This translates to as few as $21 \%$ of accident victims dying before reaching a medical facility. ${ }^{18}$

The level of enforcement and safety regulations is also a key factor in the prevalence of RTCs. The lack of rigorous enforcement of laws against drunk driving and the non-use of safety helmets may increase the risk of RTCs. Drunk driving legislation is not well established for over a third of the world's population. This is supported by a study which reported that in places such as Ghana, 21\% of randomly selected drivers displayed blood alcohol concentrations above $80 \mathrm{mg} / \mathrm{dL}$, while only $0.4 \%$ of their Danish counterparts tested positive for high alcohol concentrations. ${ }^{19,20}$ While Ghana reports a total of 26.6 road traffic deaths per hundred thousand of their population, Denmark has a more acceptable figure of 3.5. ${ }^{20,21}$ Only $33 \%$ of countries adequately enforce motorcyclist and cyclist helmet use. ${ }^{21}$ This is despite helmets being proven to reduce the death rates among motorcyclists by $42 \%$ in geographical areas with well-established health care systems. ${ }^{11}$

\section{Adventure Sports}

Adventure sports tourism is a growing travel industry but it also constitutes a significant proportion of death in travellers. The ocular risks of trauma resulting from bungee-jumping and sky-diving have been discussed previously in this journal. ${ }^{22}$

\section{Water Sports}

Water sports-related accidents constitute a significant proportion of deaths from adventure sports among travellers. In one study, drowning was suspected to be responsible for up to $20 \%$ of traumatic deaths in travellers, depending on the location. ${ }^{23}$ Further analysis has elucidated that, apart from the risks associated with lack of knowledge, experience and negligence towards safety precautions, travellers participating in these activities are especially susceptible to dangers in the sea, such as envenomation or traumatic wounds sustained from marine creatures or corals. All of these could potentially result in death by drowning. ${ }^{24}$ In particular, research demonstrates that travellers who died while snorkeling, either by drowning, cardiac events or hypoxia, were found to lack experience, physical or mental fitness, and proper equipment. Moreover, those who participated in scuba-diving tended to disregard pre-established plans; many died from barotrauma, air emboli and decompression illness. ${ }^{12}$ Watersports can also include the use of motorised vehicles which carry an inherent risk of injury. In one reported case, a passenger ferryboat, which was sailing in an area restricted to parasailers, collided with a speedboat that was towing a parasailer. ${ }^{24}$ In another instance, two travellers riding on separate jet skis accidentally collided, resulting in the death of one traveller. ${ }^{24}$

\section{Mountaineering and Trekking}

Adventure sports such as mountaineering and trekking are also a significant cause of death in travellers. A study conducted in the Himalayas found that the death rate among mountaineers, mostly well-acclimatised elite mountaineers, on peaks of above $8000 \mathrm{~m}$ was $1.63 \% .{ }^{25} \mathrm{~A}$ similar study conducted on Mount Blanc found that the death rate of mountaineers scaling the mountain was $12 \%{ }^{26}$ These fatalities were often due to equipment failure, panic, poor judgment, overconfidence and avalanches. However, the greatest cause of casualties was as a result of falls; high altitude illness in trekkers could conceivably have contributed to some of these fatal falls. ${ }^{27}$ Fatalities from trekking were frequently attributable to trauma, illness and acute mountain sickness. Additionally, deaths during trekking activities may be exacerbated by absence of medical support staff on 
expeditions. ${ }^{27}$ High altitude trekkers should be familiar with the clinical presentation of high altitude pulmonary and cerebral oedema and should be familiar with how to achieve a safer ascent profile and use acetazolamide prophylaxis in some cases. ${ }^{28}$ In summary, adventure sports' accidents often involve the lack of proper equipment, experience, preparation or safety protocols; these factors expose the traveller to the risk of traumatic injuries.

\section{Wildlife Attacks}

Another notable cause of death among travellers is large mammal attacks, worsened by the growing popularity of safaris and other tourist attractions. Being in close proximity to wildlife carries inherent risks, which primarily stem from the ignorance of how to safely interact with wild animals. This is evident in a study where seven tourists were killed in encounters with wild animals in South Africa, caused by lions, hippopotami and an elephant. Three of the deaths by lions were due to the failure of the tourists to heed warnings to stay within the safe confines of their vehicles. The remaining death had resulted from the lack of adequate security and warning notifications by the nature reserve's management. The deaths caused by the hippopotami were due to a tourist's breach of the fenced safety area and another tourist who deliberately approached a hippo. The last death was caused by a distressed elephant, which attacked a vehicle and gored the victim to death. These tragic cases illustrate the need to raise further awareness of safety precautions when interacting with these animals, and for the safari travel industry to bolster safety protocols to ensure the safety of their visitors. ${ }^{29,30}$

\section{Homicide and Terrorist Attacks}

Homicide is dissimilar from the above causes of death as it is not purely accidental. Several studies have shown that homicides may account for $16 \%$ of traveller deaths, although this figure varies widely between regions. ${ }^{31}$ Africa accounted for the highest number of homicides, followed by Asia and Latin America. The lowest rates were recorded in Eastern Europe. Such deaths can be attributed to the use of firearms, knives, cutting or drilling equipment, battery, suffocation or blast. The use of firearms, which had the highest incidence of mortality, accounted for $34 \%$ of deaths in one study. ${ }^{31}$ Homicide victims are often first subject to other crimes such as robbery and sexual assault. The risk of sexual assault and rape, especially among lone female travellers, during international travel has been discussed previously. ${ }^{32}$ Homicides also tend to cluster around hotels, bars and nightclubs, and also occur more frequently in the evening. Studies have shown that these crimes are typically caused by being in unfamiliar surroundings, being inattentive, showcasing jewelry and money, and a general lack of understanding of local criminal methods. ${ }^{12}$ Increasingly, travellers are advised to consult a reputable source of travel security information, such as the British Foreign and Commonwealth Office ${ }^{33}$ or other foreign affairs agency, in evaluating the level of threat of terrorist attacks in a given destination. A comprehensive treatment of terrorist attack risks is beyond the scope of the current review.

\section{Review Highlights}

\section{What Is Already Known?}

Road traffic collisions are the single greatest cause of death in international travellers, yet there has been very little emphasis placed on travel-related traumatic injury and death in the travel medicine literature.

\section{What This Study Adds?}

This narrative review article describes the major traumatic risks associated with travel across international boundaries. Statistics on travel trauma-related mortality and road traffic deaths are provided. The risks posed by adventure sports, including water sports and high altitude trekking, are highlighted. Large mammal attacks in the context of safari travel are also discussed. Homicide and terrorist attacks and physical trauma resulting from stampedes at mass gatherings are explored. A checklist of travel health recommendations will serve as a guide to travel medicine practitioners counselling patients in travel health clinics.

\section{Ceremonies and Stampedes}

Mass gatherings, such as religious pilgrimages, sporting events and music festivals, present a risk of physical trauma as a result of stampedes and traumatic asphyxia. Pilgrims, sports tourists and festival goers should be counselled about the risk of stampede and how best to respond in the event of an emergency. Manoochehry and Rasouli describe stampede as the "most dreaded trauma risk" in Muslim Hajj pilgrims. ${ }^{34}$ The Hajj stampede of 2015 led to the tragic death of 2431 pilgrims at Mina in Saudi Arabia. The fatalities mostly resulted from head injury and traumatic asphyxia. The authors advocate heightened safety measures by the Ministry of Health, including more effective disaster planning, development of triage systems for dealing with mass casualties, crowd management and deployment of more trauma surgeons at overcrowded pilgrimage sites. The use of computer technology and camera surveillance may help to locate missing pilgrims and alert their tour group leaders to their location. Telemedicine also has potential for use in this disaster setting. Similar approaches may be effective at major international sporting events such as the Olympic Games and the World Cup football tournament. Additional traumatic risks at international music festivals include lightning strikes in outdoor venues, fires, and tympanic membrane rupture from loud music.

\section{Conclusion and Travel Health Recommendations}

Travel medicine has a role in reducing the burden of international travel-related trauma. A recent study revealed that travellers attending a pre-travel health clinic place high priority on personal safety and that it ranks as their major concern alongside accessing medical care abroad. ${ }^{35}$ Travellers should be educated about the traumatic risks of their intended travel activities and encouraged to plan their travels prudently as nearly $66 \%$ of injuries sustained among 
Table 1. Travel Health Precautions to Reduce the Risk of Traumatic Injury

\begin{tabular}{|c|c|}
\hline Travel Scenario & Precautionary Measure \\
\hline General & $\begin{array}{l}\text { Carry a mobile phone and keep a list of numbers and addresses of relevant authorities (police, hospitals, travel insurance, embassy). } \\
\text { Contact the embassy for comprehensive local information. } \\
\text { Opt for licenced package tours. } \\
\text { Use official transport services. } \\
\text { Stay in reputable accommodation and in safe areas. } \\
\text { Refrain from excessive alcohol consumption. } \\
\text { Receive training on basic first aid. } \\
\text { Refrain from taking 'selfies' or using selfie sticks in dangerous situations. }{ }^{38}\end{array}$ \\
\hline Motorist trauma & 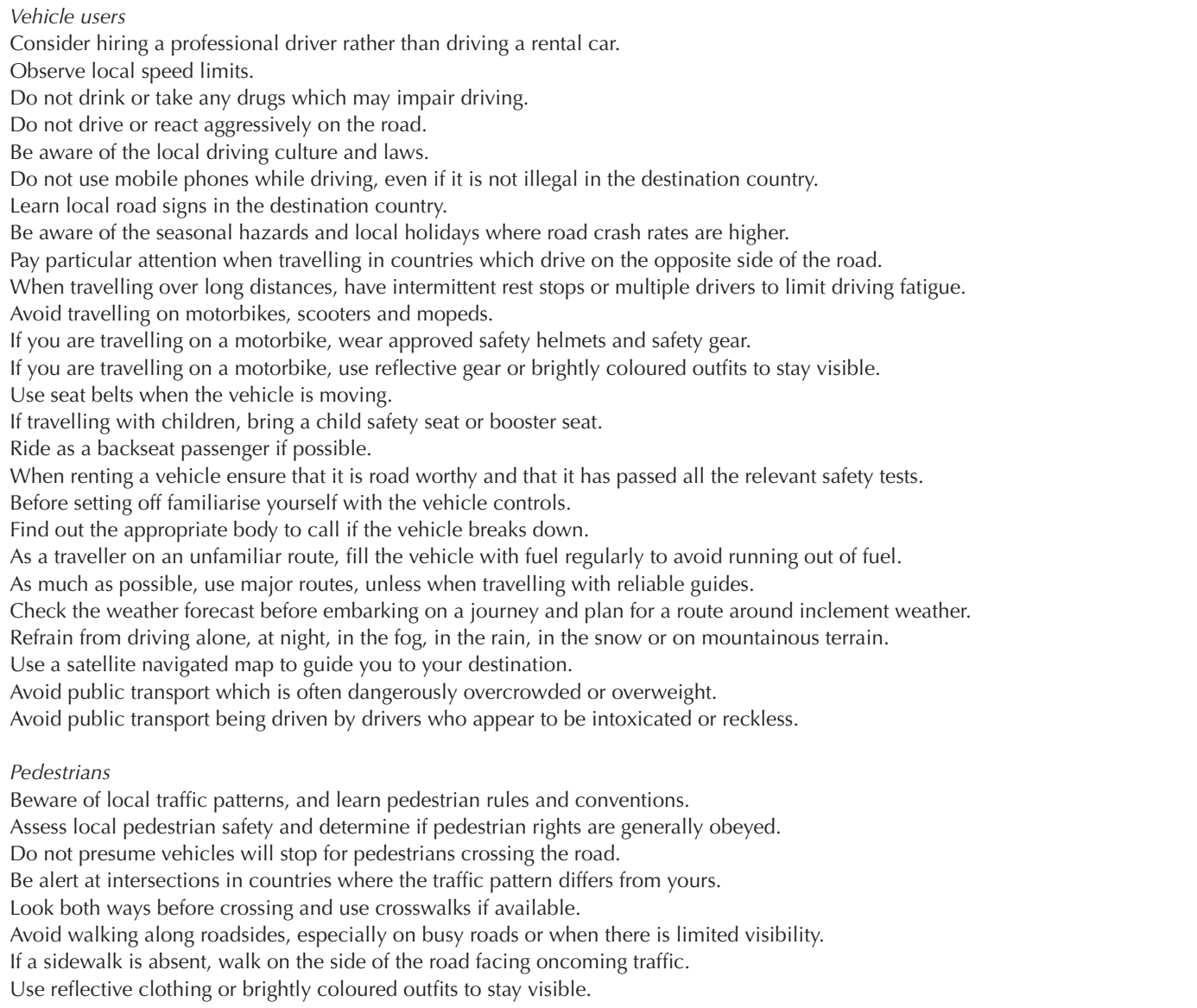 \\
\hline Other transportation risks & $\begin{array}{l}\text { Travel on scheduled flights, ferry or train services. } \\
\text { Avoid travelling in poor weather. } \\
\text { Avoid small vessels, especially at night or during poor weather. } \\
\text { Identify locations of personal flotation devices and fire extinguishers before departing. } \\
\text { Avoid dangerously overcrowded or overweight vessels. } \\
\text { Ensure the vessel has completely stopped before entering or exiting. } \\
\text { Avoid walking close to or on railway tracks. } \\
\text { Avoid crossing railway tracks unnecessarily. }\end{array}$ \\
\hline
\end{tabular}

Seek advice from the relevant bodies regarding the presence of dangerous animals locally.

Use modern equipment which meets international standards.

Check all equipment before participating in the activity.

Consider using mobility aids such as hiking poles.

Acclimatise gradually to high altitude.

Adventure

sports
Seek relevant pre-medical check-ups to ensure an adequate level of health for the intended activity.

Select reputable companies to guide the intended activity.

Opt for a company which has a medical professional available throughout the duration of the activity.

Participants of water-related sports should ensure that they do not venture out of this safe area.

Participants of water-related sports should wear a personal flotation device.

Scuba divers should use a diver-down flag and a buddy system.

Skiers and jet ski riders should refrain from speeding, especially in crowded areas. 
travellers are preventable. ${ }^{36}$ This is particularly relevant in the case of last minute travellers or travellers whose itineraries are uncertain. ${ }^{37}$ To supplement pre-travel health consultations, travellers visiting travel agencies, GPs and travel clinics should be equipped with a comprehensive checklist outlining travel-associated injury risks and the appropriate precautions they should observe (Table 1).

\section{Authors' Contributions}

GTF developed the idea for the review. GTF and IJL conducted the literature search. IJL prepared the first draft of the manuscript, which was edited and expanded by GTF. Both authors read and approved the final version of the manuscript.

\section{Conflict of Interest Disclosures}

None.

\section{Ethical Approval}

Not applicable.

\section{Funding/Support}

None received.

\section{References}

1. UNWTO. UNWTO Tourism Highlights 2016 edition. http:// www.e-unwto.org/doi/pdf/10.18111/9789284418145. Accessed November 29, 2017. Published 2016.

2. Connolly R, Prendiville R, Cusack D, Flaherty G. Repatriation of human remains following death in international travellers. J Travel Med. 2017;24(2). doi:10.1093/jtm/taw082.

3. Flaherty GT, Lim Yap K. Bibliometric analysis and curriculum mapping of travel medicine research. J Travel Med. 2017;24(5). doi:10.1093/jtm/tax024.
4. Lozano R, Naghavi M, Foreman K, et al. Global and regional mortality from 235 causes of death for 20 age groups in 1990 and 2010: a systematic analysis for the Global Burden of Disease Study 2010. Lancet. 2012;380(9859):2095-2128. doi:10.1016/s01406736(12)61728-0.

5. Tonellato DJ, Guse CE, Hargarten SW. Injury deaths of US citizens abroad: new data source, old travel problem. J Travel Med. 2009;16(5):304-310. doi:10.1111/j.1708-8305.2009.00318.x.

6. Hargarten SW, Baker TD, Guptill K. Overseas fatalities of United States citizen travelers: an analysis of deaths related to international travel. Ann Emerg Med. 1991;20(6):622-626. doi:10.1016/S01960644(05)82379-0.

7. Paixao ML, Dewar RD, Cossar JH, Covell RG, Reid D. What do Scots die of when abroad? Scott Med J. 1991;36(4):114-116. doi:10.1177/003693309103600406.

8. Prociv P. Deaths of Australian travellers overseas. Med J Aust. 1995;163(1):27-30.

9. Stewart BT, Yankson IK, Afukaar F, Medina MC, Cuong PV, Mock C. Road Traffic and Other Unintentional Injuries Among Travelers to Developing Countries. Med Clin North Am. 2016;100(2):331343. doi:10.1016/j.mcna.2015.07.011.

10. Carey MJ, Aitken ME. Motorbike injuries in Bermuda: a risk for tourists. Ann Emerg Med. 1996;28(4):424-429. doi:10.1016/ S0196-0644(96)70009-4.

11. Leggat PA, Fischer PR. Accidents and repatriation. Travel Med Infect Dis.2006;4(3-4):135-146.doi:10.1016/j.tmaid.2005.06.008.

12. Spira AM. Preventive guidance for travel: trauma avoidance and medical evacuation. Dis Mon. 2006;52(7):261-288. doi:10.1016/j. disamonth.2006.08.002.

13. Mclnnes RJ, Williamson LM, Morrison A. Unintentional injury during foreign travel: a review. J Travel Med. 2002;9(6):297-307. doi:10.2310/7060.2002.30168.

14. MacPherson DW, Guerillot F, Streiner DL, Ahmed K, Gushulak BD, Pardy G. Death and dying abroad: the Canadian experience. J Travel Med. 2000;7(5):227-233. doi:10.2310/7060.2000.00070.

15. Petridou E, Askitopoulou H, Vourvahakis D, Skalkidis Y, Trichopoulos D. Epidemiology of road traffic accidents during pleasure travelling: the evidence from the Island of Crete. 
Accid Anal Prev. 1997;29(5):687-693. doi:10.1016/S00014575(97)00038-9.

16. World Health Organization. Road safety: Estimated number of road traffic deaths, 2013. http://gamapserver.who.int/gho/ interactive_charts/road_safety/road_traffic_deaths/atlas.html. Accessed November 29, 2017. Published 2016.

17. Mock CN, Jurkovich GJ, nii-Amon-Kotei D, Arreola-Risa C, Maier $R V$. Trauma mortality patterns in three nations at different economic levels: implications for global trauma system development. JTrauma. 1998;44(5):804-812. doi:10.1097/00005373-199805000-00011.

18. Toroyan T, laych K, Peden M. Global Status Report on Road Safety. Geneva (Switzerland): World Health Organization, Department of Violence and Injury Prevention and Disability; 2013.

19. MockC,Asiamah G,AmegashieJ. A Random, Roadside Breathalyzer Survey of Alcohol Impaired Driving in Ghana. J Crash Prev Inj Control. 2001;2(3):193-202. doi:10.1080/10286580108902564.

20. Ross HL. Prevalence of alcohol-impaired driving: an international comparison. Accid Anal Prev. 1993;25(6):777-779. doi:10.1016/0001-4575(93)90042-U.

21. World Health Organization. Road safety: Estimated road traffic death rate (per 100,000 population) 2013. 2016. Available at: http://gamapserver.who.int/gho/interactive_charts/road_safety/ road_traffic_deaths2/atlas.html. Accessed January 29, 2017.

22. Tang JZM, Flaherty GT. An Eye on Travel: An Overview of TravelRelated Ocular Complications. Int J Travel Med Glob Health. 2017;5(3):74-76. doi:10.15171/ijtmgh.2017.16.

23. Guptill KS, Hargarten SW, Baker TD. American travel deaths in Mexico. Causes and prevention strategies. West J Med. 1991;154(2):169-171.

24. Leggat PA, Leggat FW. Reported fatal and non-fatal incidents involving tourists in Thailand, July 1997-June 1999. Travel Med Infect Dis. 2003;1(2):107-113. doi:10.1016/s14778939(03)00040-1.

25. Westhoff JL, Koepsell TD, Littell CT. Effects of experience and commercialisation on survival in Himalayan mountaineering: retrospective cohort study. BMJ. 2012;344:e3782. doi:10.1136/ bmj.e3782.

26. Marsigny B, Lecoq-Jammes F, Cauchy E. Medical mountain rescue in the Mont-Blanc massif. Wilderness Environ Med. 1999;10(3):152-
156. doi:10.1580/1080-6032(1999)010[0152:MMRITM]2.3 $\mathrm{CO} ; 2$.

27. Burtscher M. Climbing the Himalayas more safely. BMJ. 2012;344:e3778. doi:10.1136/bmj.e3778.

28. Flaherty GT, Kennedy KM. Preparing patients for travel to high altitude: advice on travel health and chemoprophylaxis. Br J Gen Pract. 2016;66(642):e62-64. doi:10.3399/bjgp16X683377.

29. Leggat PA, Durrheim DN, Braack L. Traveling in wildlife reserves in South Africa. J Travel Med. 2001;8(1):41-45. doi:10.2310/7060.2001.1232.

30. Durrheim DN, Leggat PA. Risk to tourists posed by wild mammals in South Africa. J Travel Med. 1999;6(3):172-179. doi:10.1111/j.1708-8305.1999.tb00856.x.

31. Uzun I, Celbis O, Baydar CL, Alkan N, Arslan MN. Foreigners dying in Istanbul. J Forensic Sci. 2009;54(5):1101-1104. doi:10.1111/ j.1556-4029.2009.01120.x.

32. Kennedy KM, Flaherty GT. The Risk of Sexual Assault and Rape During International Travel: Implications for the Practice of Travel Medicine. J Travel Med. 2015;22(4):282-284. doi:10.1111/ jtm.12201.

33. British Foreign and Commonwealth Office. Foreign travel advice. https://www.gov.uk/foreign-travel-advice. Accessed January 23, 2018. Published 2018.

34. Manoochehry S, Rasouli HR. Recurrent human tragedy during Hajj. Int J Travel Medicine Glob Health. 2017;5(1):36-37. doi:10.15171/ijtmgh.2017.07.

35. Flaherty GT, Chen B, Avalos G. Individual traveller health priorities and the pre-travel health consultation. J Travel Med. 2017;24(6). doi:10.1093/jtm/tax059.

36. Wadhwaniya S, Hyder AA. Pre-travel consultation without injury prevention is incomplete. J Travel Med. 2013;20(4):217-220. doi:10.1111/jtm.12041.

37. Flaherty G, Md Nor MN. Travel itinerary uncertainty and the pre-travel consultation--a pilot study. J Travel Med. 2016;23(1). doi:10.1093/jtm/tav010.

38. Flaherty GT, Choi J. The 'selfie' phenomenon: reducing the risk of harm while using smartphones during international travel. J Travel Med. 2016;23(2):tav026. doi:10.1093/jtm/tav026. 